\title{
Review: self-help interventions improve anxiety and mood disorders
}

den Boer PCAM, Wiersnia D, van den Bosch RJ. Why is self-help neglected in the treatment of emotional disorders? A meta-analysis. Psychol Med 2004;34:959-71.

Q How effective are self-help interventions for people with clinically significant emotional disorders?

METHODS

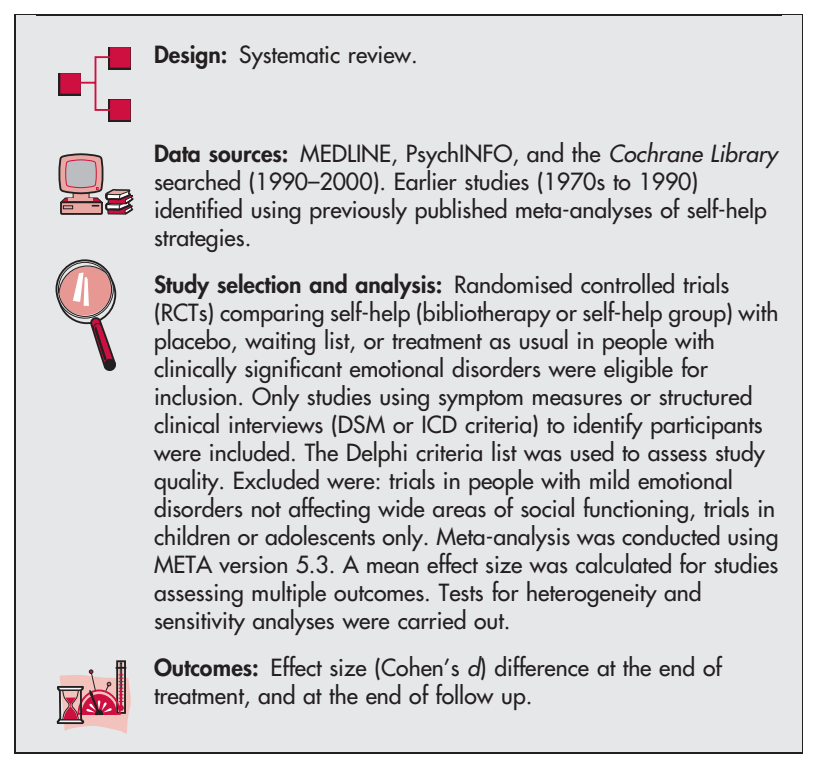

\section{MAIN RESULTS}

Fourteen RCTs (13 on bibliotherapy, one on a self-help group) met inclusion criteria. Studies were in people with mood disorders (nine RCTs), anxiety disorders (four RCTs), or both mood and anxiety disorders (one RCT). Self-help interventions had a greater effect on symptom measures than control at the end of treatment (16 comparisons, 490 people, treatment length 4-12 weeks; effect size difference $0.84,95 \%$ CI 0.65 to 1.02; no significant heterogeneity). Self-help interventions also had a greater effect than control at the end of follow up, but there was significant heterogeneity among trials (five comparisons, 130 people, follow up at 8-37 weeks; effect size difference $0.76,95 \%$ CI 0.09 to 1.42 , heterogeneity reported as significant).

\section{CONCLUSIONS}

Self-help interventions (mainly bibliotherapy) are more effective than control treatments (placebo, waiting list, or usual treatment) for clinically significant emotional disorders (anxiety and mood disorders).

\section{NOTES}

The authors note that limitations of their study included the reliance on the searches of published meta-analyses to identify studies published before 1990. Most of the included RCTs were small, had poor or unclear allocation concealment methods, had short intervention periods, and did not blind assessors or conduct intention to For correspondence: Dr Peter C A M den Boer, Department of Psychiatry, University Hospital Groningen, PO Box 30.001, 9700 RB Groningen, the Netherlands

Sources of funding: Not stated. treat analyses. Meta-analysis was not performed by type of self-help received or by type of emotional disorder.

\section{Commentary}

motional disorders, including the various types of mood and anxiety - disorders, are widespread. For example, an epidemiological study in Ontario found that the 1 year prevalence rates for anxiety disorders were $9 \%$ for men and $16 \%$ for women, while the rates for mood disorders were $3 \%$ for men and $6 \%$ for women. ${ }^{1}$ Over $76 \%$ of those with an anxiety disorder and $46 \%$ of those with a mood disorder did not seek treatment for these problems. Given these figures, it is clear that there will never be enough trained mental health professionals to treat all those in need, and that, for whatever reasons, most people will not seek traditional treatments. What is needed is a public health approach by which more people with these disorders can be helped.

The meta-analysis by den Boer et al suggests that self-help treatments are a promising alternative to traditional treatments. There are a variety of different types of self-administered treatments for emotional disorders, including bibliotherapy, audiotape programmes, computer based programs, multimedia computer packages, interactive voice response systems, web based systems, stepped care approaches, etc. ${ }^{2}$ Such selfadministered treatments offer several advantages: they broaden the range of treatments available to consumers; they increase the accessibility of treatments (most can be done at home); they are relatively inexpensive in comparison with face-to-face professional treatment; they encourage consumer choice and active participation; and they work. The average effect sizes reported by den Boer et al are large and they appear to be as effective as face-to-face professional treatment. Moreover, Vincent et al came to a similar conclusion in their review. ${ }^{2}$

Unfortunately, the authors found only one randomised controlled trial of self-help/mutual aid groups for people with emotional disorders. More well controlled studies are needed, however, studies with less rigorous methodology and randomised trials of self-help groups for people with other concerns, suggest the promise of self-help groups. ${ }^{3}$ The recent emergence of online support groups is another innovation that could be useful for people with emotional disorders.

There are several implications for change in professional practice. For those people who do seek help for emotional problems, the first professional that they are most likely to contact is their family doctor. ${ }^{1}$ Vincent et al have shown that both primary care patients and physicians are receptive to the use of self-help treatments, ${ }^{2}$ although currently the emphasis is on pharmacological treatments or referral to psychiatrists or other mental health specialists. Self-help treatments can provide mental health professionals with an alternative to placing people seeking treatment on waiting lists. Also, it is possible that these treatments could be disseminated to other gatekeepers, such as the clergy. den Boer et al have illustrated that it is important to develop complementary and alternative approaches to mental health treatment.

$$
\text { Geoffrey Nelson and Colleen Loomis }
$$
Wilfrid Laurier University, Waterloo, Canada

1 Offord D, Boyle M, Campbell D, et al. Mental Health in Ontario: Selected findings from the Mental Health Supplement to the Ontario Health Survey. Toronto: Ontario Ministry of Health, Premier's Council on Health, Wellbeing, and Social Justice, 1994.

2 Vincent N, Walker JR, Katz A. Self-help approaches in primary care. In: Watkins PL, Clum GA, eds. Handbook of Self-Help Therapies. Mahwah, NJ: Lawrence Erlbaum Associates (in press).

3 Kyrouz EM, Humphreys K, Loomis C. A review of the effectiveness of selfhelp mutual aid groups. In: White BJ, Madara EJ, eds. A Review of Research on the Effectiveness of Self-Help Mutual Aid Groups, 7th edn. Cedar Knolls, NJ: American Self-Help Clearinghouse, 2003:71-86. 